DOI 10.37882/2223-2982.2020.10.38

\title{
СЕМАНТИЧЕСКИЙ СУБЪЕКТ, СРЕДСТВА ЕГО ЧАСТИЧНОГО, КОСВЕННОГО ВЫРАЖЕНИЯ И ФОРМАЛЬНОГО ВЫРАЖЕНИЯ (НА МАТЕРИАЛЕ АНГЛИЙСКОГО И РУССКОГО ЯЗЫКОВ) ${ }^{1}$
}

\section{SEMANTIC SUBJECT, MEANS OF ITS \\ PARTIAL, INDIRECT EXPRESSION AND FORMAL EXPRESSION (ON THE MATERIAL OF ENGLISH AND RUSSIAN LANGUAGES) \\ A. Chervoniy \\ A. Pavlenko}

Summary: In the article the means of partial, generalized and indirect expression of a semantic subject, as well as the means of its complete formal elimination from the composition of the statement are analyzed on the material of the English and Russian languages.

The means of partial, generalized and indirect expression of a semantic subject, as well as its elimination from the composition of the statement constitute a lexico-grammatical paradigm. Partial, generalized and indirect expression of a semantic subject is carried out by lexical means of the English language, and its elimination is implemented in a number of syntactic constructions in which the focus of attention is given to the object of influence of the subject or the process itself. In case of the complete formal elimination of a semantic subject in the English language passive constructions are mainly used, in Russian uncertainpersonal and impersonal sentences are used in the same case.

Keywords: semantic subject, partial expression, indirect expression, generalization, elimination, syntactic construction.
$\Pi$ онятие «субъект» вошло в научный обиход во времена Аристотеля. С тех пор этот термин получил широкое употребление в философии, логике, психологии, истории, политологии, юриспруденции, лингвистике и других научных дисциплинах. В настоящее время он довольно часто используется и в обыденной речи, когда с определенной долей негативной коннотации говорят о каком-л. человеке, часто неизвестном.

В лингвистике термин «субъект» употребляется в нескольких значениях: субъект логический - то, о чем говорят, субъект синтаксический - подлежащее, субъект коммуникативный - тема сообщения, субъект психологический - исходное представление, семантический
Червоный Александр Михайлович

Д.филол.н., дочент, Таганрогский институт имени А.П. Чехова (филиал) ФГБОУ ВПО «РГЭУ (РИНХ)» ckutrik@yandex.ru

Павленко Александр Евгеньевич

Д.филол.н., дочент, Таганрогский институт имени А.П. Чехова (филиал) ФГБОУ ВПО «РГЭУ (РИНХ)»

alex_pavlenko@inbox.ru

Аннотация: В статье на материале английского и русского языков рассмотрены средства частичного, обобщенного и косвенного выражения семантического субъекта, а также средства его полного формального устранения из состава высказывания.

Средства частичного, обобщенного и косвенного выражения семантического субъекта, а также его устранения из состава высказывания составляют лексико-грамматическую парадигму. Частичное, обобщенное и косвенное выражение семантического субъекта осуществляется лексическими средствами английского языка, а его элиминация реализуется в ряде синтаксических конструкций, в которых в фокусе внимания оказывается объект воздействия субъекта или сам процесс.

При полном формальном устранении семантического субъекта в английском языке преимущественно используются пассивные конструкций, в русском языке-неопределенно-личные и безличные предложения.

Ключевые слова: семантический субъект, частичное выражение, косвенное выражение, обобщение, устранение, синтаксическая конструкция.

субъект - реальный деятель [1, с. 497-498]. Данная дифференциация объясняется целью и уровнем проводимого анализа языкового материала. В нашем исследовании рассматривается семантический субъект, т.е. реальный деятель, агенс, каузирующий и производящий некие действия, переживающая, размышляющая, продуцирующая речевые высказывания субстанция, которая по своим физиологическим, физическим, психологическим параметрам соответствует набору характеристик, свойственных человеку. По сути дела, нами рассматриваются маркеры присутствия человека в реальной действительности и его референции в языке/речи.

В данной работе основное внимание уделяется ча-

Исследование выполнено при финансовой поддержке Российского фонда фундаментальных исследований (РФФИ) в рамках научного проекта № 19-012-00062 «Полифония семантического субъекта (на материале русского, французского, английСкого и немецкого языков)», проводимого в ФГБОУ ВО «РГЭУ (РИНХ)»; руководитель - доктор филол. наук, доцент, заведующий кафедрой немецкого и французского языков А.М. Червоный 
стичным, обобщенным, косвенным средствам выражения субъекта, а также рассматривается его полное формальное устранение из состава высказываний английского языка в сопоставлении с литературным переводом на русский язык.

В качестве языкового материала нами было использовано произведение У.С. Моэма. «Эшенден, или британский агент» [6; 7]. В результате проведенного компонентного и сопоставительного анализа были выявлены средства частичного, обобщенного и косвенного выражения семантического субъекта, а также средства его полного формального устранения из состава высказывания.

\section{І. Частичное выражение субъекта. Каузативные конструкшии}

\section{Рассмотрим предложение:}

- I had them manicured this morning - Я сделал маникюр сегодня утром.

Описываемая ситуация, предполагает интерсубъектное взаимодействие, включающее каузатора и исполнителя.

В приведенной каузативной конструкции лексически выражен каузатор действия, тогда как реальный деятель формально не представлен.

В переводе предложения на русский язык невозможно определить сам ли говорящий сделал себе маникюр или он обратился к специалисту в парикмахерскую или салон красоты. Отсутствием местоимения myself в английском высказывании подчеркивается неучастие говорящего в осуществлении указанного действия, реальный деятель лексически не представлен, - он выводится из контекста.

В каузативных конструкциях обозначена лишь часть функционала семантического субъекта, а именно: каузация некоего действия. Вследствие своей коммуникативной избыточности реальный исполнитель действия довольно часто в высказывании не находит своего выражения.

\section{II. Генерализируюшее выражение семантического субъекта в обобшаюших высказываниях}

Английские местоимения, используемые в выражениях со значением обобщения, вследствие широкой семантики не конкретизируют семантический субъект, который чаще всего известен участникам коммуникации. Использование местоимений с обобщающим значением позволяет коммуникантам, реализуя прагматические цели, усилить свою аргументацию и при этом однозначно не называть реального деятеля [5]. Формально в ан- глийском предложении семантический субъект выражен местоимениями «оne», «уоu».

1) «One should do what one can to mitigate the rigours of war, » remarked R. - Надо по возможности скрашивать тяготы военного времени, - сказал $\mathrm{P}$.

2) «lt's just as well not to take any more risk than one need, » he said - осторожность не мешает, - произнес он.

3) You have to in my profession - Иначе нельзя при моей профессии.

Неопределенно-личным высказываниям английского языка соответствуют безличные предложения русского языка.

III. Косвенный способ выражения субъекта. Метонимическое выраукение семантического субъекта. Средства передвижения, соматизмы

1. Довольно часто в высказывании семантический субъект может быть представлен каким-л. элементом человека, его той или иной телесной частью.

1)...... and his theory is that when his back was turned the woman slipped a drug into his glass. -.... и, согласно его теории, женщина, когда он отвернулся, высыпала в его бокал какой-то наркотик.

При сопоставлении английского выражения и его русского эквивалента проявляется лексическая асимметрия: в русском переводе субъект выражен личным местоимением 3-го лица единственного числа, тогда как в английском варианте соматизмом «the back» - «спина».

2) ......you never knew what inquisitive ears were pricked up to catch any useful piece of information that might fall from your lips....- никогда не знаешь чьи любопытные уши готовы уловить любые полезные сведения, которые могут сорваться с твоих уст.... В данном обобщающем высказывании семантически субъект и его речевая деятельность лексически обозначены органами речи и слуха - «уста (губы)» - «lips» и «уши» - «ears».

2. Рукотворные предметы, которые произведены и используются агенсом, заменяя в языке формально невыраженного субъекта, в то же время когнитивно, в языковом сознании указывают на присутствие человека. Таким образом, антропоморфный след фиксируется сознанием, которое и воссоздает реальную картину происходящего.

1) One day, on the way through Siberia, the train stopped at some station.... - Однажды, когда мы ехали по Сибири, поезд остановился на каком-то полустан- 
ке......

«Поезд» - одно из средств передвижения, которое изготовлено человеком и им эксплуатируется, поэтому, несмотря на формальную невыраженность семантического субъекта его присутствие и его роль осознаются на ментальном уровне.

2) ... the bill came - принесли счет... Совершенно очевидно, что счет был кем-то доставлен. Но этот некто ввиду известности или коммуникативной невостребованности не нашел своего лексического выражения.

3. Присутствие человека, характеристику его действий, состояний могут выражать притяжательные прилагательные.

Например: 1) His manner was pleasant and cordial - его манеры можно было назвать приятными. т.е., his помимо выражения обладания косвенным образом обозначает того, чьи манеры для окружающих приятны. Выражаемый таким образом субъект - бенефициант [4, с. 171] (субъект оценки, см. 3).

2) ... and with his every movement a wave of perfume was wafted to your nose. - При каждом движении он источал резкий парфюмерный запах. В данном примере his может быть соотнесен с агенсом - действующим лицом.

Сопоставительный анализ языкового материала лишний раз подтвердил более частотное употребление притяжательных прилагательных в английском языке, нежели в русском.

\section{IV. Формальная элиминашия семантического субъекта. Высказывания с глаголами конверсивами. Номинализашия. Пассивные конструкшии. Безличные конструкшии}

\section{1. Высказывания с глаголами-конверсивами.}

Глаголы-конверсивы используются для выражения ситуации, в которой действия взаимно направлены, например, давать-брать, присылать - получать. При этом лексемы получать, принимать и т.д. передают инертный, зависимый характер действий индивидуума, которому свойственна скорее функция адресата.

Например: «You know you ought to get material»Знаете, но вам следует получить материал.

\section{2. Номинализация.}

Воплощение процесса в форме имени достигается путем транспозиции глагола в имя. В лингвистике выделяют субъектную и объектную номинализации (термины В.Г. Гака) [3].
А) Субъектная номинализация, - проявляется в синтаксической конструкции, в которой имя находится в позиции подлежащего.

Например: 1) The explanation seems perfectly satisfactory - Представляется, что объяснение исчерпывающеe.

2) An expedition is being arranged to free my unhappy country from the tyrants - Снаряжаются экспедиционные силы для освобождения моей несчастной родины от тиранов.

3) A whistle was blown and the train started - Прозвучал свисток и поезд тронулся.

В) Объектная номинализация реализуется в конструкциях, в которых имя находится в позиции дополнения, а также после презентативов This is....., These are......

Например: 1) If you do well you'll get no thanks and if you get into trouble you'll get no help. - Если вы отлично справитесь с делом, то на благодарность не рассчитывайте, а если у вас начнутся неприятности, то помощи вы не дождетесь.

2) There was a knock at the door. It opened and the Hairless Mexican stood before them - Раздался стук. Дверь отворилась - перед ними стоял Безволосый Мексиканец.

Во втором примере наглядно представлен процесс выявления реального деятеля - семантического субъекта, идущего от незнания к знанию, от действия к действующему лицу, его производящему.

3. Пассивные конструкции. В фокусе внимания в пассивных конструкциях оказывается объект воздействия субъекта, тогда как сам он оказывается вне языковой актуализации.

А) Одушевленный объект воздействия.

1) I was sent to prevent the Bolshevik Revolution - Я был послан, чтобы предотвратить большевистскую революцию.

2) He chanced soon after his arrival to go to a party and was there introduced to a middle-aged Colonel - Bскоре после прибытия ему довелось побывать на приеме, где его представили полковнику средних лет.

В) Неодушевленный объект воздействия.

Конструкции-результативы.

1) It was furnished with a heavy mahogany suite uphol- 
stered in green velvet and the chairs were set primly round a large table. - Гостиная была меблирована громоздкой, красного дерева мебелью с обивкой из зеленого бархата, кресла чинно расставлены вокруг большого стола.

2).....The Rome express was signalled...- Объявили римский экспресс.......

3) The floor by his side was strewn with burnt-out butts and the air was thick and grey - На полу под диваном валялись окурки, и воздух был прокуренный и сизый.

Несмотря на формальное отсутствие семантического субъекта антропоморфное значение лексических единиц, обозначающих проявление его жизнедеятельности, не оставляет сомнения в реальной реализации свойственных человеку функций. Проявление активных свойств субъекта выражено семантикой английских причастий.

Следует отметить, что в отдельных предложениях возможно параллельное выражение одушевленного и неодушевленного объектов воздействия имплицитного(ых) субъекта (субъектов).

1) On the house at which Ashenden had been asked to call there was a board up to announce that it was for sale.... - На доме, в который пригласили Эшендена, висело объявление....

\section{4. Безличные конструкции.}

Семантический субъект имплицитно представлен в безличных по форме, но не по содержанию, синтаксических конструкциях.

- Of course, a lot of nonsense is talked about the value of human life. - На самом деле, о ценности человеческой жизни говорится много вздора. Антропоморфным маркером данного высказывания служит семантика глагола to tell - говорить, рассказывать.

Таким образом, средства частичного, обобщенного и косвенного выражения семантического субъекта, а также его устранения из состава высказывания составляют лексико-грамматическую парадигму.

Частичное, обобщенное и косвенное выражение семантического субъекта осуществляется лексическими средствами английского языка, а его элиминация реализуется в ряде синтаксических конструкций, в которых в фокусе внимания оказывается объект воздействия субъекта или сам процесс.

Следует также отметить преимущественное использование пассивных конструкций английского языка и неопределенно-личных и безличных предложений русского языка при полном формальном устранении семантического субъекта из структуры предложения.

\section{ЛИТЕРАТУРА}

1. Арутюнова Н.Д. Субъект. М.: Советская энциклопедия, 1990. - 683 с.

2. ак В.Г. Номинализация сказуемого и устранение субъекта // Синтаксис и стилистика. - М.: Наука, 1976. - С. 85-102.

3. Циммерлинг А.В. Субъект состояния и субъект оценки // Логический анализ языка. Образ человека в культуре и языке. Н.Д. Арутюнова, И.Б. Левонтина (отв. ред.). М., Индрик, 1999, С. 221-228.

4. ЧейфУ.Л. Значение и структура языка. - М.: Прогресс, 1975.- 432 с.

5. Червоный А.М. Семантический субъект в обобщающих высказываниях русского и французского языков // Язык и действительность. Научные чтения на кафедре романских языков им. В.Г. Гака. Сборник статей по итогам IV международной конференции. 2019. С. 432-440.

6. Моэм У.С. Эшенден, или Британский агент (пер. А. Ливергант) [Электронный ресурс] https://online-knigi.com/page/157165 (дата 06ращения: 10.08.2020).

7. Maugham, W.S. Ashenden: or, The British Agent. [Электронный ресурс] https://www.fadedpage.com/books/20160522/html.php (дата 06ращения: 10.08.2020).

(с Червоный Александр Михайлович (ckutrik@yandex.ru ), Павленко Александр Евгеньевич (alex_pavlenko@inbox.ru ). Журнал «Современная наука: актуальные проблемы теории и практики» 